\title{
PREVENTION OF SHIVERING DURING LOWER SEGMENT CESAREAN SECTION;
}

Comparison of prophylactic use of ketamine, and ketamine plus midazolam during spinal anaesthesia

\section{Dr. Ashfaq Ahmed, Brig Mohammad Aslam}

ABSTRACT: Objectives: To compare the efficacy of low-dose prophylactic use of ketamine with ketamine plus midazolam for the prevention of shivering caused by spinal anesthesia, during lower segment cesarean section. Main Outcome Measures: Heamodynamic monitoring, avoidance of lactic acidosis/ increased carbon dioxide production and patient satisfaction. Design: Prospective Randomized Controlled trial. Place: Department of Anesthesia and ICU PNS Shifa Karachi. Duration of study: March 2010 to June 2010 . Patients and Methods: 100 ASA-I \& II consecutive patients who reported for LSCS in PNS Shifa Hospital were studied. In this double-blind study, patients were randomly allocated to receive ketamine alone (Group I, $n=50$ ), and ketamine plus midazolam $(G r o u p ~ I I, ~ n=50)$. After standardized Spinal anesthesia, a shivering was recorded at 5 min intervals for 15 minutes. Results: Shivering was observed in $9 / 50$ (18\%) patients of group I (Ketamine only) as compared to only $2 / 50(4 \%)$ patients in Group II (ketamine + midazolam) $(p=0.025)$ which is statically significant. The two groups were comparable regarding distribution of age $(p=0.37)$, BMI $(p=0.27)$ and duration of surgery. Results were analyzed by using chi square test. Conclusions: The efficacy of i.v. ketamine plus midazolam is better as compared to lowdose i.v. ketamine alone in preventing shivering in lower segment Cesarean Section patients, during spinal anesthesia.

Key words: Anesthetic techniques, regional; premedication, midazolam; temperature, regulation; Cesarean Section.

Article Citation

Ahmed A, Aslam M. Prevention Of Shivering During Lower Segment Cesarean Section; Comparison of prophylactic use of ketamine, and ketamine plus midazolam during spinal anaesthesia. Professional Med J 2013;20(3): 409-415.

\section{INTRODUCTION}

Shivering is uncomfortable and unpleasant for the patient and may interfere with monitoring of electrocardiogram, blood pressure (BP), and oxygen saturation ${ }^{1}$. It increases oxygen consumption (200$400 \%)^{2,3}$, lactic acidosis and carbon dioxide production ${ }^{2}$. These effects are often poorly tolerated by the pregnant women as these patients having limited cardiac and pulmonary reserves ${ }^{1}$.Spinal and epidural anesthesia leads to hypothermia by causing vasodilatation and subsequent internal redistribution of heat, the accompanying thermoregulatory impairment due to an altered perception of temperature in the blocked dermatomes by the hypothalamus ${ }^{4}$. Shivering associated with spinal and epidural anesthesia is occurring in up to $56.7 \%$ of patients ${ }^{5}$.

In previous studies various drugs have been investigated for prevention or treatment of post op shivering including pethidine, sufentanyl, alfentanyl, tramadol, physostigmine ${ }^{6,7}$. Ketamine differs from others in increasing the plasma concentration of norepinephrine and arteriolar peripheral resistance ${ }^{8}$. Ketamine, given intravenously (i.v.), appeared quite useful in reducing shivering during regional anaesthesia (about $70 \%)^{8}$. Midazolam is a commonly used sedative and anesthetic adjuvant, has been found to be effective in the prevention of postoperative shivering by impairing thermoregulatory controls ${ }^{10}$. Typical doses of midazolam, GABA receptor agonist, reduce the shivering threshold in $50 \%$ humans ${ }^{10}$. The combination of ketamine plus midazolam reduces the shivering threshold in about $97 \%$ of the patients ${ }^{11}$. The rationale of present study is to compare the efficacy of ketamine alone and combination of ketamine plus midazolam for prevention of shivering after Lower segment cesarean section so that much better choice can be used.

\section{PATIENTS AND METHODS}

Prospective randomized double blind comparative study was conducted at Department of Anesthesia, Intensive Care and Pain Management PNS SHIFA Karachi, after the approval of Hospital Ethical 
committee. The first 100 ASA 1 and ASA-2 consecutive patients who fulfilled the inclusion criteria were included in the study. Informed consent was obtained from each patient. The approved protocol established by the clinical study committee was used in the study overseeing the ethics and legal aspects of clinical investigations. The patients were randomly (envelope randomization) allocated (I \& II) to receive ketamine $0.5 \mathrm{mg} / \mathrm{kg}$ (group I, $\mathrm{n}=50$ ) or $0.25 \mathrm{mg}$ $\mathrm{kg}^{-1}+$ midazolam $37.5 \mathrm{\mu g} \mathrm{kg}^{-1}$ intravenous (group II, $\mathrm{n}$ $=50)$.

Spinal anesthesia was administered in sitting position and patients were turned to left lateral tilt $15^{\circ}$ position. The treatment drugs were prepared, diluted to a volume of $2 \mathrm{ml}$ and presented as coded syringes by an anesthesiologist who was not involved in the management of patients or in grading of the patients' shivering. During surgery, active skin surface warming and warmed i.v fluid warming were not used and room temperature was set at $25^{\circ} \mathrm{C}$. All patients received $4 \mathrm{~L} /$ min oxygen by facemask. Shivering was graded (scale of wrench and the scale proposed by Crossley and Mahajan ${ }^{10}$ ) as:

$0=$ no shivering

$1=$ piloerection or peripheral vasoconstriction but no visible shivering

$2=$ muscular activity in only one muscle group

$3=$ muscular activity in more than one muscle group but not generalized,

$4=$ shivering involving the whole body.

After 15 min of spinal anesthesia and concomitant administration of a prophylactic dose of one of the study drugs, patient who shivered to grade 0-2 was considered "no shivering" and who shivered 3 or more, the prophylaxis was regarded as ineffective. Intravenous (i.v.) pethidine $25 \mathrm{mg}$ was administered to control shivering.

The data was analyzed using Statistical Package for
Social Sciences (SPSS) Version 10. Mean+SD was calculated for age, height \& weight (BMI) and duration of surgery. Frequency of shivering was calculated in percentage. A $p$-value of $<0.05$ was considered statistically significant.

\section{RESULTS}

One hundred ASA I/II LSCS patients undergoing procedure in spinal anesthesia, were randomly selected for the study. They were divided in two equal groups which were comparable regarding distribution of age, BMI and duration of surgery. None of the subjects were dropped out or lost at any point in the study. No any active warming of patient was done to prevent shivering. The Mean age was $28 \pm 3.7$ and 27 \pm 3 years, BMI $24.8 \pm 1.5$ and $24.3 \pm 1.2$ in group I and II respectively (Table I). Mean duration of surgery was $74 \pm 18$ and $69 \pm 14$ minutes in group I and II respectively (Table I).

\begin{tabular}{|l|c|c|}
\hline \multicolumn{1}{|c|}{ Variables } & Group I $(\mathbf{n = 5 0 )}$ & Group II $(\mathbf{n = 5 0 )}$ \\
\hline Age (years) & $28 \pm 3.74$ & $27.56 \pm 3.04$ \\
\hline BMI & $24.78 \pm 1.51$ & $24.35 \pm 1.22$ \\
\hline $\begin{array}{l}\text { Duration of } \\
\text { surgery (min) }\end{array}$ & $74 \pm 18$ & $69 \pm 14$ \\
\hline \multicolumn{2}{|c|}{ Table-I. Descriptive statistics of variables with respect } \\
to groups
\end{tabular}

After 15 minutes of prophylactic dose of studied drugs, shivering (grade $3 \& 4$ ) was observed in only two patients $(4 \%)$ of group II (ketamine + midazolam) as compared to 9 patients (18\%) in Group I (Ketamine only) as shown in table-ll. The efficacy of prophylactic ketamine plus midazolam (group II) in preventing shivering was significantly high as compared with the ketamine alone (group I) ( $96 \%$ vs. $82 \% \mathrm{P}=0.025)$ as presented in table-III. Effectiveness of drug was also observed with rest to age group and BMl but significant difference was not observed as presented in figure 1 and figure 2. 


\begin{tabular}{|c|c|c|c|}
\hline Shivering & Group-I $(\mathbf{n = 5 0 )}$ & Group-II $(\mathbf{n}=\mathbf{5 0})$ & Total \\
\hline Grade $0-2$ & $41(82 \%)$ & $48(96 \%)$ & $89 \%$ \\
\hline Grade 3-4 & $9(18 \%)$ & $2(4 \%)$ & $11 \%$ \\
\hline
\end{tabular}

Table-Il. Shivering score with respect to groups

\begin{tabular}{|l|c|c|c|}
\hline Shivering & $\begin{array}{c}\text { Group-I } \\
(\mathbf{n}=\mathbf{5 0})\end{array}$ & $\begin{array}{c}\text { Group-II } \\
(\mathbf{n}=\mathbf{5 0})\end{array}$ & \multirow{2}{*}{ P-value } \\
\hline Effective & $41(82 \%)$ & $48(96 \%)$ & \multirow{2}{*}{0.025} \\
\hline Ineffective & $9(18 \%)$ & $2(4 \%)$ & \\
\cline { 1 - 2 } & &
\end{tabular}

Table-Ill. Comparison of efficacy of study drugs ketamine alone (group I) and combination of ketamine + midazolam (group-II) in preventing shivering. Chi-Square $=5.005 d f=1$

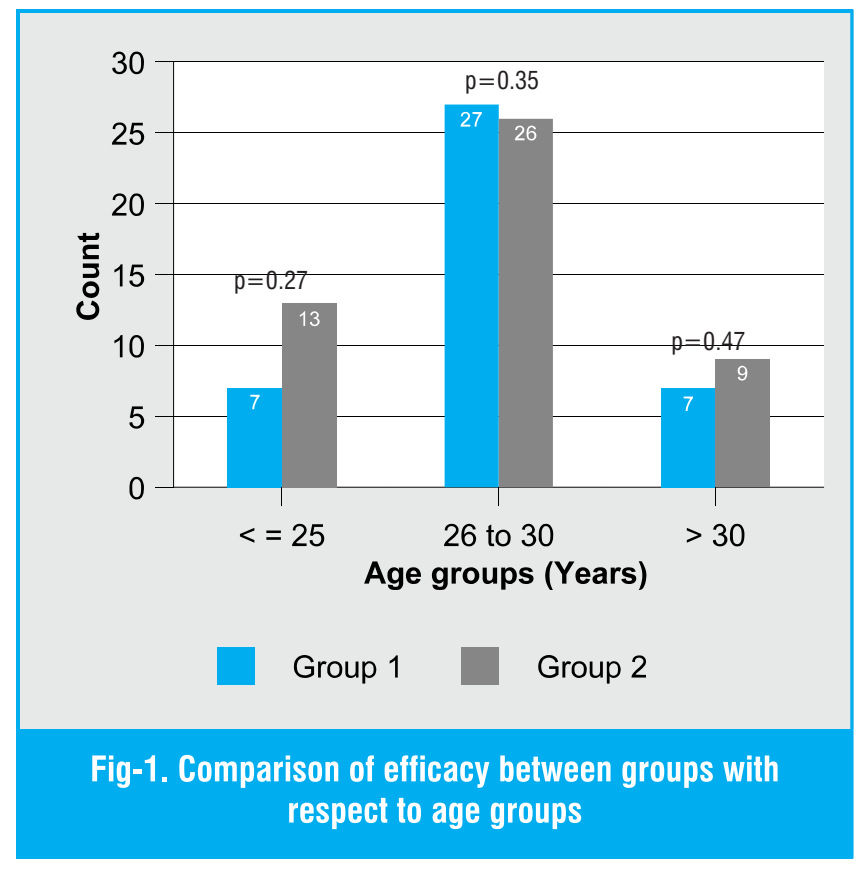

\section{DISCUSSION}

It is concluded in this study that prophylactic use of ketamine $0.25 \mathrm{mg} \mathrm{kg}^{-1}$ and midazolam $37.5 \mu \mathrm{g} \mathrm{kg}^{-1}$ i.v. is better than ketamine $0.5 \mathrm{mg} \mathrm{kg}^{-1}$ i.v. alone in preventing shivering related to spinal anesthesia during cesarean section.

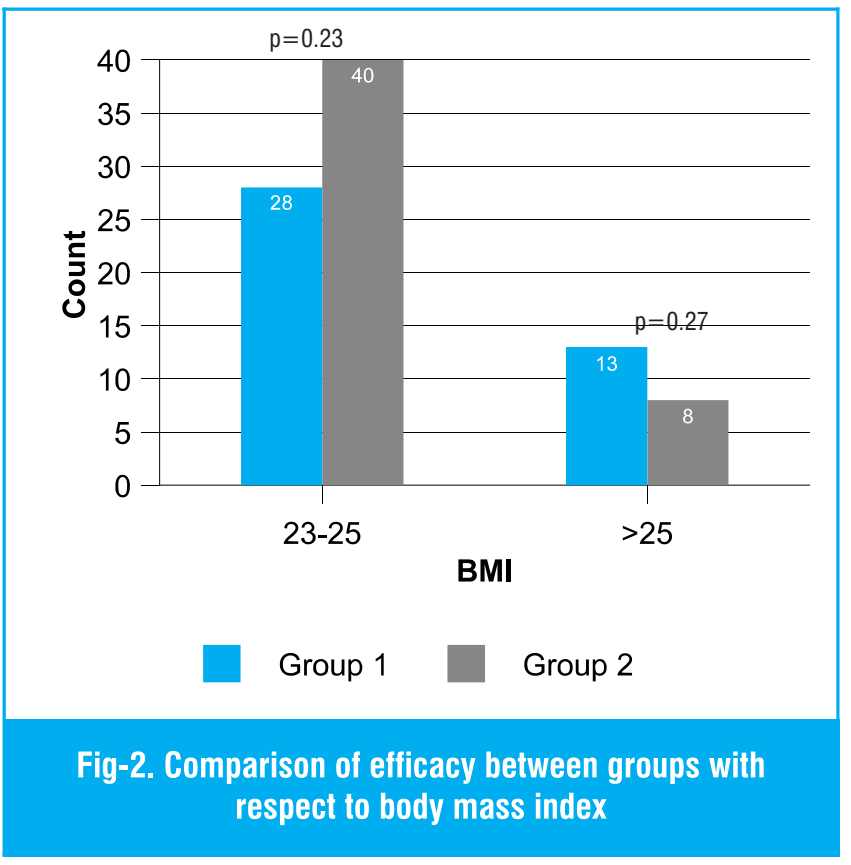

The temperature regulating system of mammals is divided into three components: thermo sensors and afferent neural pathways, integration system of thermal inputs, and effector pathways (autonomic and behavioral) $^{23}$. There is a modulation of neural transmission by the nucleus raphe magnus (inhibitor) and locus subcoeruleus (facilitator). The efferent pathway begins in the hypothalamus, makes multiple connections with the reticular formation in the midbrain, Pons, and medulla, and ends at the alphamotor neurons. The main reactions activated by efferent pathways in response to hypothermia are vasoconstriction, nonshivering thermogenesis (described in neonates), and shivering ${ }^{12}$.

Shivering is an oscillatory and involuntary muscle contraction that increases metabolic heat production. In addition to heat, there is marked increase in oxygen consumption and carbon dioxide production ${ }^{13}$ with potential risk of complications in patients with cardiovascular or pulmonary impairment. Hypothermia during regional anaesthesia is common ${ }^{4}$ and can be nearly as severe as that observed during general anaesthesia ${ }^{4}$. 
There are three principal reasons for hypothermia under spinal anaesthesia. First, spinal anaesthesia leads to an internal redistribution of heat from the core to the peripheral compartment ${ }^{25}$. Secondly, with loss of thermoregulatory vasoconstriction below the level of the spinal block, there is increased heat loss from body surfaces. Lastly, there is altered thermoregulation under spinal anaesthesia characterized by a $0.5^{\circ} \mathrm{C}$ decrease in vasoconstriction and shivering thresholds'.

Kurz and colleagues ${ }^{1}$ showed that, midazolam does not produce substantial inhibition of thermoregulation. Goold and colleagues ${ }^{14}$ have shown that diazepam premedication prevents postoperative shivering ${ }^{24}$.

Ketamine, which is a competitive receptor antagonist of N-methyl-D-aspartic acid (NMDA), has a role in thermoregulation at various levels. It probably controls shivering by non-shivering thermo-genesis either by action on the hypothalamus or by the $\beta$-adrenergic effect of norepinephrine ${ }^{11}$. Ketamine causes sympathetic stimulation and vasoconstriction in patients at risk of hypothermia. This effect of ketamine is in contrast to that of midazolam which reduces corebody temperature by inhibiting tonic thermoregulatory vasoconstriction ${ }^{15}$. It is probable that ketamine prevent the arterio-venous shunt vasodilatation normally induced by midazolam. Since these shunts are under sympathetic control ${ }^{16}$, it seems plausible that ketamine acts centrally to inhibit the effect of midazolam. Ketamine has many other pharmacological properties such as blocking amine uptake in the descending inhibitory monoaminergic pain pathways, interacting with muscarinic receptors, having a local anaesthetic action, and being a $\mathrm{K}$ opioid agonist. Various pharmacological treatments including i.v. administration of the opioids meperidine, alfentanil, and nalbuphine; the non-opioid analgesic tramadol, ${ }^{6}$ ondansetron, dolasetron; the 5-HT3 antagonists; and the cholinomimetic agent physostigmine ${ }^{22}$ for postanaesthetic shivering have been used; however, these drugs have unavoidable side-effects include hypotension, hypertension, sedation, respiratory depression, and nausea and vomiting, ${ }^{21}$ which restricts their usage.

Sharma and Thakur ${ }^{8}$ reported that ketamine IV $0.5 \mathrm{mg}$ $\mathrm{kg}^{-1}$ was effective in the treatment of shivering after general and regional anesthesia. In their study, only two patients had hallucinations and 4 patient had delirium.

Honarmand $A$ and Safavi M. $\mathrm{R}^{11}$ compared saline, ketamine, midazolam, and ketamine plus midazolam and concluded that Prophylactic use of ketamine 0.25 $\mathrm{mg} \mathrm{kg}^{-1}$ plus midazolam $37 \mu \mathrm{g} \mathrm{kg}{ }^{-1}$ i.v. was more effective than ketamine $0.5 \mathrm{mg} \mathrm{kg}^{-1}$ i.v. alone or midazolam $75 \mathrm{\mu g} \mathrm{kg}^{-1}$ i.v. alone in preventing shivering developed during regional anesthesia which is in favour of hypothesis. Sagir and colleagues ${ }^{15}$ compared placebo, ketamine, granisetron, and a combination of ketamine and granisetron for the prevention of shivering caused by regional anesthesia, and found that the incidence of shivering was $55 \%$ in the control group.

Yi JW and collegues ${ }^{17}$ evaluated intrathecal meperidine and Techanivate $\mathrm{A}$ and collegues $^{18}$ also evaluated intrathecal fentanyl $20 \mathrm{mcg}$ for prevention of shivering after cesarean section and showed a $30 \%$ reduction in its incidence ${ }^{25}$. there are authors who suggest the use of intrathecal meperidine or fentanyl for prevention of postoperative shivering ${ }^{17,18}$.

Kinoshita and colleagues ${ }^{19}$ showed that during spinal anesthesia, infusion of low-dose ketamine prevents decreases in the body temperature of patients sedated with propofol. Ketamine has been shown to prevent shivering without producing hemodynamic alterations in patients undergoing regional anaesthesi $\mathrm{a}^{20}$. This data is consistent with the anti-shivering effects of premedication with ketamine observed in the present study without significant hemodynamic changes. 
Generali $\mathrm{J} A$ and Cada $D \mathrm{~J}^{21}$ studied combination of granisetron plus ketamine for the prevention of shivering in regional anesthesia. They observed shivering in $17.5 \% \quad(n=40)$ with combination of drugs. This is in contrast to our study where combination of ketamine plus midazolam showed only 2 patients (4\%) shivered to grade 4 . This indicates that combination of ketamine plus midazolam is more efficient in preventing shivering as compare combination of ketamine plus granisetron. Duration of surgery, in previous study by. Sharma and Thakur ${ }^{8}$ Honarmand and M. R. Safavi ${ }^{11}$ was ranging from 70 \pm 10 minutes and in our study it was ranging from 69 \pm 14 minutes, hence the results were also comparable.

Reda S. Abdelrahman ${ }^{22}$ concluded that I.V. midazolam plus ketamine or tramadol plus ketamine is better than midazolam or tramadol for prophylaxis of postspinal shivering, whereas the midazolam plus ketamine combination is superior to tramadol plus ketamine combination.

In our study, the prophylactic use of ketamine $0.25 \mathrm{mg}$ $\mathrm{kg}^{-1}$ and midazolam $37.5 \mu \mathrm{g} \mathrm{kg}^{-1}$ i.v. was more effective than ketamine $0.5 \mathrm{mg} \mathrm{kg}^{-1}$ i.v alone in preventing shivering related to regional anesthesia. These results are comparable to the above studies conducted by Sharma and Thakur ${ }^{8}$ Kinoshita and colleagues ${ }^{19}$ Sagir et $\mathrm{al}^{15}$ and A. Honarmand and M. R. Safavi ${ }^{11}$ and supports the hypothesis. In our study two patients shivered to grade 4 in group II (ketamine+ midazolam). This is in contrast to study done by A. Honarmand and M. R. Safavi ${ }^{11}$, where not a single patient has observed grade 4 shivering with ketamine + midazolam. This may be due to increased sample size in our study $(n=50)$ as compared to above mentioned study $(n=30)$. Further more both genders were studied in above mentioned study, whereas in our study only female gender was studied which is more prone to develop shivering as compared to male gender.
In summary, ketamine was reported to be quite useful in spinal and epidural anesthesia, where it provided sedation and analgesia. It is clear from our and other studies that the combination of ketamine and midazolam is more efficacious in preventing shivering that is associated with regional anesthesia, It is probable that ketamine prevented the arteriovenous shunt vasodilation normally induced by midazolam. Since these shunts are under sympathetic control, it seems plausible that ketamine acts centrally to inhibit the effect of midazolam, which is in support of the hypothesis.

\section{CONCLUSIONS}

The efficacy of i.v. ketamine $(0.5 \mathrm{mg} \mathrm{kg}-1)$ in preventing shivering is less as compared to combination i.v. ketamine plus midazolam $(0.25 \mathrm{mg}$ $\mathrm{kg}-1+37.5 \mu \mathrm{g} \mathrm{kg}-1)$ for shivering prophylaxis in lower segment Cesarean Section patients, under spinal anesthesia. Combination of ketamine plus midazolam may be a better alternative to other drug therapy for treating shivering in patients under regional anesthesia. Further studies based on increased sample size are suggested in our population to get the maximum benefits of the combined ketamine plus midazolam therapy.

\section{Copyright $\subset 21$ Jan, 2013.}

\section{REFERENCES}

1. Kurz A, Sessler DI, Narzt E, et al. Postoperative hemodynamic and thermoregulatory consequences of intraoperative core hypothermia, J Clin Anesth 1995;7:359-66.

2. Sessler DI, Rubinstein EH, Moayeri A. Physiological responses to mild perianesthetic hypothermia in humans, Anesthesiology 1991;75:594-610.

3. Ciofolo MJ, Clergue F, Devilliers C, Ben Ammar M, Viars $P$ - Changes in ventilation, oxygen uptake, and carbon dioxide output during recovery from isoflurane anesthesia. Anesthesiology 1989;70:737-41.

4. Chen JC, Hsu SW, Hu LH. Intrathecal meperidine attenuates shivering induced by spinal anesthesia. 
Ma Zui Xue Za Zhi, 1993:31:19-24.

5. Jeon YT, Jeon YS, Kim YC, Bahk JH, Do SH, Lim YJ. Intrathecal clonidine does not reduce post-spinal shivering. Acta Anaesthesiol Scand 2005;49:1509-13.

6. Tsai YC, Chu KS, A comparison of Tramadol,amitryptaline and mepridine for postepidural anesthetic shivering in parturients. Aneth Analg,2001:93;1288-92.

7. Kamalipour H, Avestimehr S. A comparative study on the effect of Tramadol and Pethidine on postoperative shivering. Anesth Pain Intens Care, 2007;11:84-89.

8. Sharma Dr, Thakur JR. Ketamine and shivering. Anesthesia. 1990:45(3):252-3.

9. Liaq N, Khan MN, Nasir N, Khan S. Prevention of postoperative shivering by prophylactic ketamine in patients undergoing major surgeries under General Anesthesia. Ann Pak Inst Med Sci 2006;2:163-6.

10. Grover VK, Mahajan R, Yaddanapudi LN, Sudarshana $H G$, Gill KD. Efficacy of midazolam in preventing postoperative shivering. Int $\mathrm{J}$ Clin Pharmacol Ther2002;40:534-6.

11. Honarmand A, Safavi MR. Comparison of prophylactic use of midazolam, ketamine and ketamine plus midazolam. Prevention of shivering during regional anesthesia. Br J Anaesth. 2008 0ct;101:557-62.

12. Hopkin DA. Postoperative spasticity and shivering. Anesthesia 1984;39:725-6.

13. De Witte J, Sessler DI - Perioperative shivering: physiology and pharmacology. Anesthesiology, 2002;96:467-84.

14. Goold JE. Postoperative spasticity and shivering. A review with personal observations of $\mathbf{5 0 0}$ patients. Anaesthesia 1984;39:35-8.

15. Sagir O, Gulhas N, Toprak H, Yucel A, Begec Z, Ersoy 0 . Control of shivering during regional anesthesia : prophylactic ketamine and granisetron. Acta anaesthesiology Scan, 2007:51:44-9.

16. De Witte J, Sessler DI. Perioperative shivering: Pathophysiology and Pharmacology, Anesthesiology 2002;96:467-84.

17. Yi JW, Lee BJ, Han JH. Effects of intrathecal meperidine on prevention of shivering during spinal anesthesia for herniorrhaphy. Korean J Anesthesiol, 2005;49:484-9.

18. Techanivate A, Rodanant 0 , Tachawattanawisal W, Somsiri T - Intrathecal fentanyl for prevention of shivering in cesarean section. J Med Assoc Thai, 2005;88:1214-21.

19. Kinoshita T, Suzuki M, Shimada Y, Ogawa R. Effect of low-dose ketamine on redistribution hypothermia during spinal anesthesia sedated by propofol. J Nippon Med Sch 2004;7.

20. Crossley AW, Mahajan RP - The intensity of postoperative shivering is unrelated to axillary temperature. Anaesthesia, 1994;49:205-7.

21. Generali J A and Cada D J. Off-Label Drug Uses Granisetron: Postanesthetic Shivering. Hosp Pharm, 2010;45(3):208-11.

22. Reda S. Abdelrahman Prevention of shivering during regional anaesthesia: Comparison of Midazolam, Midazolam plus ketamine,Tramadol, and Tramadol plus Ketamine. Life Science Journal, 2012; 9(2).

23. Asami T, Hori T, kiyohara T, Nakashima T. Convergence of thermal signals on the reticulospinal neurons in the midbrain, pons and medulla oblongata, Brain Res Bull 1988;20:581-96.

24. Masamune T, Sato H, Okuyama K, Imai Y, Iwashita H, Ishiyama $\mathrm{T}$, et al: The shivering threshold in rabbits with JM-1232, a new benzodiazepine receptor agonist. Anesth Analg, 2009 Jul;109(1):96-100.

25. Matsukawa T, Sessler DI, Christensen R, Ozaki M, Schroeder M. Heat flow and distribution during epidural anesthesia, Anesthesiology 1995;83:96167. 


\section{AUTHOR(S):}

1. DR. ASHFAQ AHMED

Department of Anesthesiology and Intensive Care Unit PNS Shifa Hospital Karachi

2. BRIG MOHAMMAD ASLAM

Department of Anesthesia and Intensive Care Unit Combined Military Hospital Bhawalpur.

\section{Correspondence Address:}

Dr. Ashfaq Ahmed,

Graded Anesthestist,

Department of Anesthesiology and Intensive Care Unit

PNS Shifa Karachi

ashfaq.anesthesia@gmail.com

Article received on: $\quad 07 / 05 / 2012$ Accepted for Publication: 21/01/2013 Received after proof reading: 15/03/2013

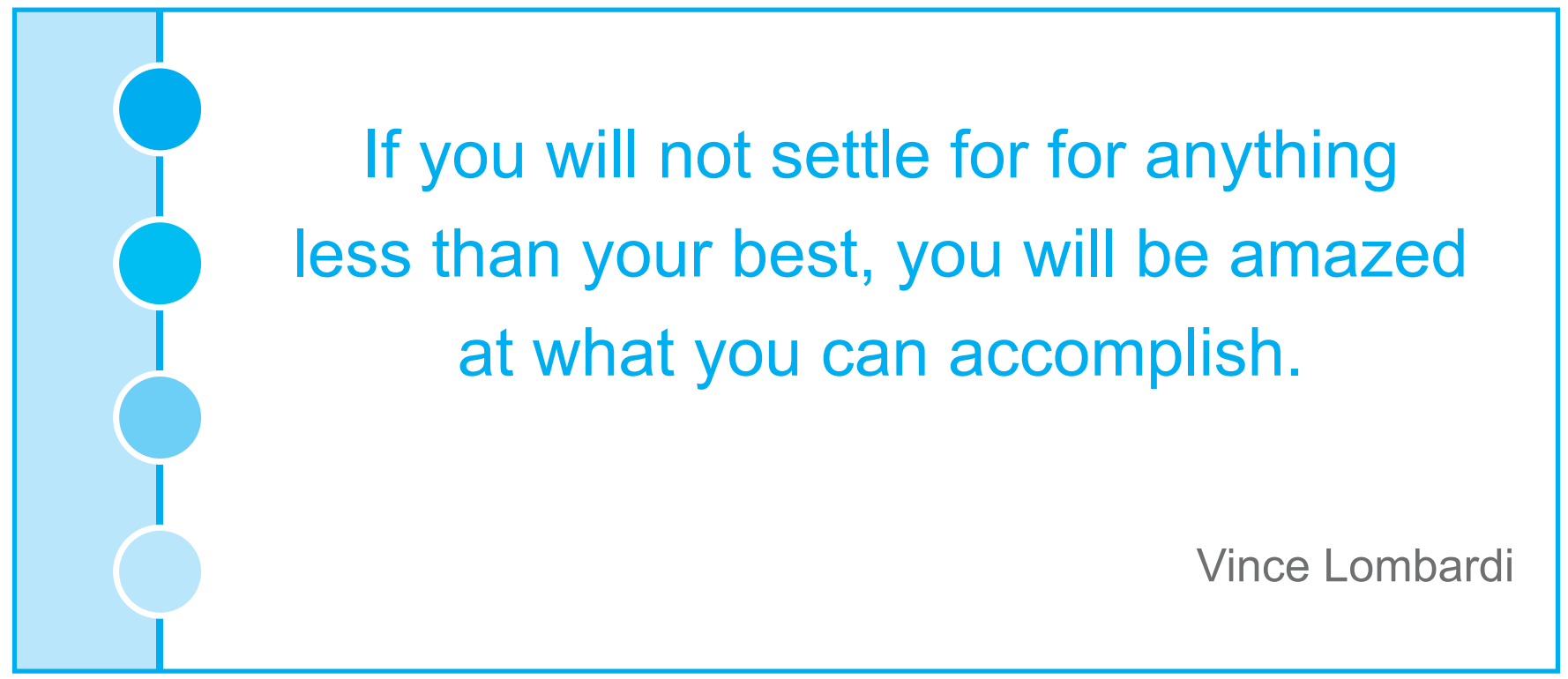

